\title{
P 104 FIVE YEARS ON: THE INCREASING USE OF ULTRASOUND IN A HOSPICE
}

Bernadette Lee. Princess Alice Hospice, Esher, UK

\subsection{6/bmjspcare-2014-000654.145}

Background Since 2008, several new doctors have attended the Focused Abdominal UltraSound in Palliative Care course. The course taught the examination protocols for ascites, liver, urinary tract and deep vein thrombosis (DVT). A log book was kept with the scanner.

Aims The aims were to audit:

the frequency of use

whether the course examination protocols were followed

the impact of having ultrasound

whether cleaning of the transducer was recorded

Information from the log book and patient records were used to complete the audit.

Results In the last 3 years, the number of scans increased from 22 to 40 . There was a trend for patients who might need paracentesis to be assessed before admission was requested.

All 125 scans followed examination protocols.

The clinical indications were confirmation of ascites (97), urinary bladder (14), hydronephrosis (3) and groin DVT (1).

\begin{tabular}{|c|c|c|c|c|c|c|c|c|}
\hline \multirow[b]{2}{*}{ Year } & \multirow[b]{2}{*}{$\begin{array}{l}\text { New } \\
\text { doctors } \\
\text { trained }\end{array}$} & \multirow{2}{*}{$\begin{array}{l}\text { Number } \\
\text { of } \\
\text { doctors } \\
\text { doing } \\
\text { scans }\end{array}$} & \multirow[b]{2}{*}{$\begin{array}{l}\text { Number } \\
\text { of scans }\end{array}$} & \multirow[b]{2}{*}{$\begin{array}{l}\text { Number } \\
\text { of } \\
\text { patients }\end{array}$} & \multicolumn{4}{|c|}{ Location } \\
\hline & & & & & ward & OPD & home & $\begin{array}{l}\text { nursing } \\
\text { home }\end{array}$ \\
\hline 2008 & 6 & 3 & 24 & 16 & 24 & 0 & 0 & 0 \\
\hline 2009 & 0 & 3 & 15 & 13 & 15 & 0 & 0 & 0 \\
\hline 2010 & 1 & 4 & 22 & 16 & 20 & 2 & 0 & 0 \\
\hline 2011 & 4 & 7 & 24 & 20 & 17 & 2 & 5 & 0 \\
\hline 2012 & 1 & 6 & 40 & 29 & 30 & 7 & 2 & 1 \\
\hline total & 12 & - & 125 & 94 & 106 & 11 & 7 & 1 \\
\hline
\end{tabular}


Each scan had been helpful in the clinical decision making: paracentesis were done on 22 occasions, prescription of diuretics (1), referral for PleurX drain (1) and insertion of urine catheter (12). 92\% (115/125) log entries recorded cleaning of transducer.

Conclusions There has been increasing and appropriate use of ultrasound last 5 years. The use of inpatient beds were optimised. Cleaning of the transducer needs to be done each time and recorded. Annual audit of ultrasound use is planned. 